\title{
The nutritional risk in oncology: a study of 1,453 cancer outpatients
}

\author{
Federico Bozzetti • Luigi Mariani • Salvatore Lo Vullo • \\ The SCRINIO Working Group • Maria Luisa Amerio • \\ Roberto Biffi • Riccardo Caccialanza • \\ Giovanni Capuano • Isabel Correja • Luca Cozzaglio • \\ Angelo Di Leo $\cdot$ Leonardo Di Cosmo • \\ Concetta Finocchiaro • Cecilia Gavazzi • \\ Antonello Giannoni • Patrizia Magnanini • \\ Giovanni Mantovani • Manuela Pellegrini • \\ Giuseppe M. Rovera • Lidia Rovera • \\ Giancarlo Sandri • Marco Tinivella $\cdot$ Enrico Vigevani
}

Received: 31 August 2011 / Accepted: 15 January 2012 /Published online: 7 February 2012

(C) The Author(s) 2012. This article is published with open access at Springerlink.com

\begin{abstract}
Purpose There is little information about the nutritional status of cancer outpatients because the practice of nutritional screening is rarely performed. This study aims to define the pattern of scores of nutritional risk in 1,453 outpatients and factors associated with a high nutrition risk score, to facilitate the identification of such patients by the oncologists.
\end{abstract}

\footnotetext{
F. Bozzetti

Faculty of Medicine, University of Milan,

Milan, Italy

L. Mariani $\cdot$ S. Lo Vullo

Unit of Clinical Epidemiology and Trial Organization,

Fondazione IRCCS Istituto Nazionale Tumori,

Milan, Italy

M. L. Amerio

Ospedale Cardinal Massaia,

Asti, Italy

R. Biffi

Istituto Europeo di Oncologia,

Milan, Italy

R. Caccialanza

Fondazione IRCCS Policlinico San Matteo,

Pavia, Italy

G. Capuano

Ospedale San Pietro Fatebenefratelli,

Rome, Italy
}

Methods We prospectively screened the nutritional status of cancer outpatients according to the NRS-2002 score which combines indicators of malnutrition and of severity of the disease (1-3 points, respectively). A score $\geq 3$ indicates "nutritional risk". The association of the nutritional scores with some patient/tumour/therapy-related variables was investigated through univariable and multivariable linear regression models.

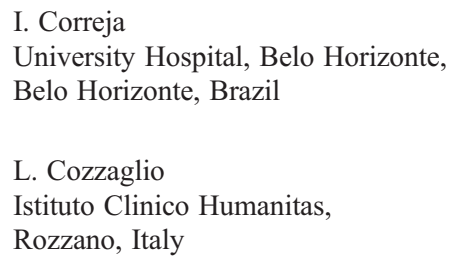

A. Di Leo

Ospedale ASL 4 Prato,

Prato, Italy

L. Di Cosmo

Azienda Universitaria Senese "Le Scotte",

Siena, Italy

C. Finocchiaro

Ospedale San Giovanni Battista,

Turin, Italy

C. Gavazzi

Fondazione IRCCS Istituto Nazionale Tumori,

Milan, Italy 
Results Thirty-two percent of outpatients were at nutritional risk. Primary tumour site, Eastern Cooperative Oncology Group score and presence of anorexia or fatigue were significantly associated with the nutrition risk score. Depending on the combination of these variables, it was possible to estimate different probabilities of nutritional risk.

Conclusions The frequency of a relevant nutritional risk was higher than expected considering the favourably selected population. The nutritional risk was associated with common clinical variables which are usually recorded in the charts and could easily alert the oncologist on the need of a further nutritional assessment or a nutritional support.

Keyword Nutritional screening · Nutritional risk · Nutritional assessment $\cdot$ Nutritional status $\cdot$ Cancer outpatients

\section{Introduction}

The European Society for Clinical Nutrition and Metabolism (ESPEN) defines nutrition risk [1] as "chances of a better or worse outcome from disease or surgery according to actual or potential nutritional and metabolic status" and nutritional screening [2] as a "rapid and simple process conducted by admitting staff or community healthcare teams". The importance of the nutritional screening cannot be overlooked: the lack of routine screening procedure was shown to leave over half the patients who are nutritionally at risk unrecognised $[3,4]$ and one fourth without nutritional support or counselling despite the presence of an active contact of the patients with health care professionals [5].
Brown and Radke [6] in the USA and, more recently, Hulmann and Cunningham [7] in UK have emphasized the specific relevance of the nutritional screening also in the treatment of weight loss in cancer patients.

The Nutritional Risk Screening (NRS 2002) is a tool developed by Kondrup and an ESPEN working group in 2002 [2] with the assumption that the indications for nutrition support are severity of undernutrition and increase in nutrition requirements resulting from disease. It was designed to include measures of both current potential undernutrition and disease severity. It was validated against 128 controlled nutrition support trials to evaluate whether it was capable to distinguish those patients with a positive clinical outcome due to nutrition intervention from those that showed no benefit of nutrition support. Subsequently, a prospective, controlled trial with 212 hospitalised patients using the NRS 2002 [8] showed an increase in nutrition intake in patients who received nutrition intervention because they were defined at nutritional risk and a shorter length of hospital stay in those with complications (usually infections) who received a nutrition intervention comparing with those without nutritional support. Since its introduction in clinical practice, NRS 2002 (briefly NRS) was used to screen the nutritional risk of a mixed patients' population and little attention was paid to the oncologic area and among them the outpatients.

However, since cancer patients represent the commonest segment of subject candidate to aggressive therapies both in the hospital and in ambulatory setting, they might present a state of malnutrition which can reduce the compliance to the oncologic therapies and can be also worsened by such treatments, this investigation focuses on screening the nutritional risk of a large population of cancer outpatients. The present

\author{
A. Giannoni \\ ASL 1-Ospedale Civile Carrara, \\ Carrara, Massa Carrara, Italy \\ P. Magnanini \\ Ospedale S.Antonio USSL 16, \\ Padua, Italy \\ G. Mantovani \\ Policlinico Universitario Cagliari, \\ Cagliari, Italy \\ M. Pellegrini \\ Presidio Ospedaliero Lucca, \\ Lucca, Italy \\ G. M. Rovera \\ ASL10-Ospedale Civile Pinerolo, \\ Pinerolo, Italy \\ L. Rovera \\ ASO Ordine Mauriziano Istituto di Ricerca e Cura del Cancro, \\ Candiolo, Italy

G. Sandri

Ospedale S.Eugenio,

Rome, Italy

\author{
M. Tinivella \\ AOU San Luigi Gonzaga, \\ Orbassano, Italy \\ E. Vigevani \\ Ospedale S. Antonio Abate, \\ Tolmezzo, Italy
}

\author{
L. Mariani $(\triangle)$ \\ Fondazione IRCCS Istituto Nazionale Tumori, \\ via G. Venezian 1, \\ 20133 Milan, Italy \\ e-mail: luigi.mariani@istitutotumori.mi.it
}


study represents the final step of multicenter prospective protocol followed by the SCRINIO Working Group and aiming to define the pattern of scores of nutritional risk in a population of cancer outpatients, and to analyze the factors associated with a high nutrition risk score. In the perspective these data could help the clinician to identify patients at nutritional risk and hence to plan a nutritional intervention.

\section{Patients and methods}

In 2003, during a scientific meeting in Milan, which involved both oncologists and nutritionists, it was clearly appreciated that there was a substantial discrepancy of view between these specialists as regard the impact that malnutrition might have on the outcome of the cancer patient and the potential role of the nutritional support. As a consequence, an open working group was constituted with the aim of steering a protocol to prospectively screen the nutritional status of the oncologic outpatients (hence the acronym SCRINIO, that is SCReenIng the Nutritional status In Oncology).

The endpoints of the study were: (1) to define prevalence and rate of malnutrition and of nutritional risk in cancer outpatients and the need for a nutritional intervention and (2) to investigate the association of some patient-related, tumour-related and therapy-related variables with the nutritional risk. The eligibility criteria included adult cancer outpatients presenting for diagnosis or therapy or follow-up to the oncologic units of different hospitals, university or scientific Institutions. Patients were excluded from the study if they were affected by endocrine diseases or they showed a severe impairment of vital organs' function.

The protocol collected some demographic data (age and sex) of the patients, oncologic data [site of primary tumour, histology, stage (defined according to the UICC classification), Eastern Cooperative Oncology Group (ECOG) performance state, oncologic therapy] and nutritional data, namely the percentage of the weight loss at different interval times before and during the illness and the body mass index (BMI). Systemic and digestive symptoms as fatigue, anorexia, nausea/vomiting, early satiety, dysgeusia/dysosmia, odynophagia/dysphagia and diarrhoea/constipation were classified semiquantitatively through a four-point score (no, mild, moderate, severe).

Finally, the risk of complications related to malnutrition was assessed through the NRS. Briefly, if the patients at the initial screening have a BMI $<20.5 \mathrm{Kg} / \mathrm{m}^{2}$ or they have lost weight in the last 3 months or they have a reduced dietary intake in the last week or they are severely ill, then they move to the final screening where a quantification of the previous parameters is completed and it summed with the severity of the disease. The final scoring ranges from 0 to 6 , being $0=$ no risk, $1-2=$ low risk, $3-4=$ medium risk and $>5=$ high risk (see Appendix 1). For age $\geq 70$ years one additional score is added. A score $\geq 3$ (we define it as "high NRS score") is considered worth requiring a further deeper nutritional assessment for a potential nutritional intervention, whereas for a lower score a periodic nutritional surveillance is usually advised. This tool has been demonstrated to have a high predictive validity and a low interobserver variation $(k=0.76)$.

The study was implemented in 2004, included clinicians of 20 (mainly Italian) centres (see Acknowledgments) and closed to accrual on December 2008 after inclusion of 1,556 cancer patients. Of these, 103 lacked NRS information and were thus excluded from analyses. Each centre got the approval for the study and the informed consent form by its own local ethics committee. The central study database was held at the Fondazione IRCCS Istituto Nazionale Tumori of Milan where data collected on each patient were entered, checked for quality and completeness and elaborated. Details on the study protocol and preliminary results on the first 1,000 patients have been recently published [9], and database was previously utilized for two publications, one on weight loss and its association with digestive and systemic symptoms [10] and one on a definition and classification of cancer cachexia [11].

\section{Statistical methods}

Descriptive analyses were based on standard statistics such as relative frequencies for categorical variables (gender, high NRS score, site of primary, UICC stage, ECOG performance status, therapy and symptoms degree) or otherwise with medians and interquartile ranges (NRS score, age). We considered anorexia in two different ways: "anorexia" as such, which simply means lack of appetite, and "anorexia syndrome", also including symptoms interfering with food intake like early satiety, taste or smell alterations, nausea/vomiting and dysphagia/odynophagia [12]. The syndrome degree was defined as the maximum degree recorded for each of the contributing symptoms.

The patterns of association between NRS score and age, gender, site of primary, UICC stage, ECOG PS, therapy and symptoms were investigated by means of univariable and multivariable linear regression models. NRS score was alternatively treated as a continuous variable, or as categorical toward a classification threshold of 3 (NRS $<3$, NRS $\geq 3$ ), denoting nutritional risk. Two-sided $P$ values below 0.05 were considered significant. We used SAS ${ }^{\text {TM }}$ and $\mathrm{R}$ software for computation. 


\section{Results}

Main series characteristics for the 1,453 patients with NRS score information, as shown in Table 1, were in general as expected for outpatients seen in the units of medical oncology, with a prevalence of advanced disease stage (III or IV according to the UICC classification, $80 \%$ of cases), good performance status ( 0 or 1 on the ECOG scale, $80 \%$ of cases) and some kind of oncologic treatment ongoing or completed ( $70 \%$ and $16 \%$ of cases, respectively). Symptoms were relatively common, but severe in only a minority of patients. As regards nutritional status, 32\% of the patients were defined at nutritional risk that is $14 \%$ were with an NRS score $>3$, and another $18 \%$ were considered worthy of further nutritional assessment because of an NRS score $=3$.

Table 2 reports mean NRS score and percentage of patients with high NRS score according to distinct patients' characteristics. In both cases, significant results were always achieved at the univariable and multivariable analyses, with tumour stage and therapy being the only exceptions. In particular, these two factors were no longer significant in the multivariable analysis of the percentage of patients with nutritional risk. Age (not shown) always failed to yield significant results.

Table 3 shows the frequency estimated by the multivariable analysis according to tumour site, ECOG performance status and the presence of symptoms (anorexia and fatigue). As regards the remaining two variables, which failed to reach statistical significance in the multivariable analysis, we arbitrarily assumed tumour stage 3 and no therapy administration as reference categories to perform the calculation. Notably, the figures were obtained incorporating a statistically significant synergistic effect of anorexia and fatigue; namely, the joint presence of both symptoms was shown to have an impact on the frequency of patients at nutritional risk exceeding that expected by summation of their distinct contributions.

It is possible to observe that the frequency of patients with high NRS, 31.8\% overall, was highly variable, ranging between a minimum of $7.9 \%$ to a maximum of $97.6 \%$. To summarize, we found that conditions exceeding a $50 \%$ frequency threshold were ECOG performance status $\geq 2$ (20.1\% of the series), or ECOG performance status $=1$ in the presence of both anorexia and fatigue $(20.4 \%$ of the series); frequencies were generally much lower and below the $50 \%$ threshold in the remaining cases, with some detrimental effect of upper GI tumours compared to other tumour sites. For instance, an upper GI patient has an $85.6 \%$ probability of high NRS score if ECOG PS $=3-4$; the probability is still high $(83.5 \%)$ when ECOG PS=1 but both symptoms are present, whereas the probability drops to $15.4 \%$ when ECOG $\mathrm{PS}=0$ and the patient is asymptomatic.
Table 1 Patient distribution according to demographic and disease characteristics

\begin{tabular}{|c|c|c|}
\hline & $n$ & $\%$ \\
\hline Overall & 1,453 & \\
\hline \multicolumn{3}{|l|}{ Gender } \\
\hline Female & 540 & 37.3 \\
\hline Male & 908 & 62.7 \\
\hline N.R. & 5 & - \\
\hline Age (years) ${ }^{\mathrm{a}}$, median (IQ range) & \multicolumn{2}{|c|}{$64.0(55-71)$} \\
\hline \multicolumn{3}{|l|}{ Site of primary tumour } \\
\hline Oral cavity & 116 & 8.0 \\
\hline Oesophagus & 80 & 5.5 \\
\hline Stomach & 206 & 14.2 \\
\hline Pancreas & 90 & 6.2 \\
\hline Small bowel & 33 & 2.3 \\
\hline Colon-rectum & 518 & 35.7 \\
\hline Lung & 217 & 15.0 \\
\hline Upper respiratory airways & 84 & 5.8 \\
\hline Other & 107 & 7.4 \\
\hline N.R. & 2 & - \\
\hline \multicolumn{3}{|l|}{ UICC stage } \\
\hline 0 & 10 & 0.9 \\
\hline I & 51 & 4.7 \\
\hline II & 150 & 13.8 \\
\hline III & 298 & 27.4 \\
\hline IV & 578 & 53.2 \\
\hline N.R. & 366 & - \\
\hline \multicolumn{3}{|l|}{ ECOG PS } \\
\hline 0 & 514 & 43.7 \\
\hline 1 & 426 & 36.2 \\
\hline 2 & 185 & 15.7 \\
\hline 3 & 47 & 4.0 \\
\hline 4 & 4 & 0.3 \\
\hline N.R. & 277 & - \\
\hline \multicolumn{3}{|l|}{ Therapy } \\
\hline Never treated & 203 & 14.0 \\
\hline Past treated & 234 & 16.1 \\
\hline Ongoing, one & 838 & 57.7 \\
\hline Ongoing, two & 164 & 11.3 \\
\hline Ongoing, three & 14 & 1.0 \\
\hline \multicolumn{3}{|l|}{ NRS 2002 score } \\
\hline 0 & 368 & 25.3 \\
\hline 1 & 336 & 23.1 \\
\hline 2 & 287 & 19.8 \\
\hline 3 & 259 & 17.8 \\
\hline 4 & 138 & 9.5 \\
\hline 5 & 53 & 3.7 \\
\hline 6 & 12 & 0.8 \\
\hline Median (IQ range) & $2(0-3)$ & \\
\hline \multicolumn{3}{|l|}{ Anorexia symptom } \\
\hline No & 683 & 47.2 \\
\hline
\end{tabular}


Table 1 (continued)

\begin{tabular}{lrc}
\hline & $n$ & $\%$ \\
\hline Mild & 362 & 25.0 \\
Moderate & 304 & 21.0 \\
Severe & 94 & 6.7 \\
N.R. & 7 & - \\
Anorexia syndrome & & \\
No & 349 & 24.1 \\
Mild & 401 & 27.6 \\
Moderate & 477 & 32.9 \\
Severe & 224 & 15.4 \\
N.R. & 2 & - \\
Fatigue & & \\
No & 455 & 31.4 \\
Mild & 536 & 37.0 \\
Moderate & 359 & 24.8 \\
Severe & 99 & 6.8 \\
N.R. & 4 & - \\
Early satiety & & \\
No & 864 & 59.6 \\
Mild & 300 & 20.7 \\
Moderate & 221 & 15.3 \\
Severe & 64 & 4.4 \\
N.R. & 4 & - \\
\hline
\end{tabular}

$N . R$. not reported, $I Q$ interquartile, UICC International Union Against Cancer, ECOG PS Eastern Cooperative Oncology Group performance status

${ }^{\mathrm{a}}$ Missing data in ten cases

\section{Discussion}

This study represents the first investigation using systematically the NRS 2002 to define the nutritional risk of cancer outpatients despite the guidelines by the American Society of Parenteral and Enteral Nutrition [13] that all patients should undergo nutritional screening dating back to 2002 . These recommendations have been quite recently replicated in ad hoc ASPEN guidelines [14] and by the National Cancer Institute [15]. However, a recent survey in UK [16] showed that $80 \%$ of specialist oncological trainees expressed uncertainty or a lack of confidence in their ability to identify malnutrition and a similar study in US radiology oncologists [17] reported that only $9 \%$ of them used body weight plus other assessment tools.

Although several screening tools are available, there is no consensus among the experts upon the best way of screening the nutritional status of cancer patients and several of these tools, including the malnutrition screening tool [18-20], the malnutrition universal screening tool [21] and the patientgenerated subjective global assessment [21-25], the subjective global assessment $[21,23,26,27]$ and the nutrition risk index $[27,28]$ are validated in oncology patients.

A large comparative study has shown that NRS 2002 has a better performance than the malnutrition universal screening tool and the nutrition risk index, compared to subjective global assessment [29]. Similarly, attempts to validate the malnutrition universal screening tool in a population with cancer showed that it was unsuitable for use because of low sensitivity and specificity $[21,30]$.

On the contrary, Sorensen et al. [31] have shown that the nutritional status determined by NRS 2002 maintained a significant independent association with complications even when adjusted for possible confounders as presence of cancer. We found that NRS 2002 is fully suitable for cancer population since many recognized prognostic factors (type of primary tumour, performance status, symptoms) parallel with the score of the NRS 2002.

The most striking finding of this study was that one third of our patients were considered with a high NRS, a percentage somewhat lower than the value (49\%) recently reported by Isenring et al. [32] on a mixed population of 191 inpatients and outpatients. Our figure is intermediate between the values extrapolated for hospitalised cancer patients from large surveys of mixed pathologies populations, which range from $27 \%$ to $43 \%$ [20, 31, 33-35], while in advanced cancer patients enrolled in palliative home care services, the nutritional risk may rise till $68 \%$ [36]. Such a percentage of nutritionally at risk outpatients is especially remarkable and worrisome when considering that patients able to attend an ambulatory consultation or therapy should represent a favourably selected segment of the cancer population.

Since a score of 3 calls for a further more exhaustive nutritional assessment, it is noteworthy that a median value of 3 was observed in patients with cancer of the oesophagus and pancreas, in those with ECOG score $\geq 2$ and in those with anorexia or fatigue of degree classified as moderate or severe. All of these factors achieved statistical significance also at the multivariable analysis (Table 2).

Even if oncologists do not feel comfortable, confident or adequately prepared to provide nutrition counselling, such a remarkable prevalence of outpatients with high nutritional risk should alert them to face actively with this issue for two reasons. First, the deleterious effects of malnutrition on compliance with oncologic therapies [37, 38] and response to treatment [39-45] are well recognized, and secondly, there is a growing experience that an early nutritional intervention when tumour burden is still limited is able to achieve a clinical benefit [46-48].

Finally, although undernutrition cannot entirely explain the progressive deterioration of the general status of the cancer patients, nevertheless, the correlation between NRS score and anorexia (which accounts for $76 \%$ of the NRS score $\geq 3$ ) is in keeping with a potential role of nutrition support in decreasing 
Table 2 Mean NRS score and percentage of patients with nutritional risk (NRS score $\geq 3$ ), according to main patients' characteristics

\begin{tabular}{|c|c|c|c|c|c|}
\hline \multirow[b]{2}{*}{ Factor } & \multirow[t]{2}{*}{ No. of pts. } & \multirow[t]{2}{*}{ Mean } & \multirow[t]{2}{*}{$P$} & \multicolumn{2}{|c|}{ Score $\geq 3$} \\
\hline & & & & $\%$ & $P$ \\
\hline \multicolumn{6}{|l|}{ Tumour site } \\
\hline Oral cavity & 116 & 1.5 & & 28.5 & \\
\hline Oesophagus & 80 & 3.1 & & 62.5 & \\
\hline Stomach & 206 & 2.3 & & 43.7 & \\
\hline Pancreas & 90 & 2.6 & $<0.0001^{\mathrm{a}}$ & 54.3 & $<0.0001^{\mathrm{a}}$ \\
\hline Small bowel & 33 & 1.1 & $<0.0001^{\mathrm{b}}$ & 6.1 & $0.0002^{\mathrm{b}}$ \\
\hline Colon-rectum & 518 & 1.5 & & 24.3 & \\
\hline Lung & 217 & 1.7 & & 28.1 & \\
\hline Upper respiratory airways & 84 & 1.4 & & 28.6 & \\
\hline Other & 107 & 1.4 & & 25.2 & \\
\hline \multicolumn{6}{|l|}{ Tumour stage } \\
\hline 0 & 10 & 0.6 & & 10.0 & \\
\hline I & 51 & 1.4 & $<0.0001^{\mathrm{a}}$ & 19.6 & $<0.0001^{\mathrm{a}}$ \\
\hline II & 150 & 1.5 & $0.0308^{\mathrm{b}}$ & 23.3 & $0.1333^{\mathrm{b}}$ \\
\hline III & 298 & 1.8 & & 33.2 & \\
\hline IV & 578 & 1.7 & & 29.8 & \\
\hline \multicolumn{6}{|l|}{ ECOG PS } \\
\hline 0 & 514 & 0.9 & & 10.1 & \\
\hline 1 & 426 & 2.0 & $<0.0001^{\mathrm{a}}$ & 35.5 & $<0.0001^{\mathrm{a}}$ \\
\hline 2 & 185 & 3.3 & $<0.0001^{\mathrm{b}}$ & 79.5 & $<0.0001^{\mathrm{b}}$ \\
\hline 3 & 47 & 4.0 & & 91.5 & \\
\hline 4 & 4 & 5.0 & & 100.0 & \\
\hline \multicolumn{6}{|l|}{ Therapy } \\
\hline Never treated & 203 & 1.6 & & 29.6 & \\
\hline Past treated & 234 & 2.1 & $0.0017^{\mathrm{a}}$ & 40.6 & $0.0052^{\mathrm{a}}$ \\
\hline Ongoing, one & 838 & 1.7 & $0.0742^{\mathrm{b}}$ & 28.8 & $0.0669^{\mathrm{b}}$ \\
\hline Ongoing, two & 164 & 1.9 & & 37.2 & \\
\hline Ongoing, three & 14 & 2.1 & & 35.7 & \\
\hline \multicolumn{6}{|l|}{ Anorexia } \\
\hline No & 683 & 1.0 & $<0.0001^{\mathrm{a}}$ & 11.0 & $<0.0001^{\mathrm{a}}$ \\
\hline Mild & 362 & 2.0 & $<0.0001^{\mathrm{b}}$ & 36.5 & $<0.0001^{\mathrm{b}}$ \\
\hline Moderate & 304 & 2.7 & & 57.9 & \\
\hline Severe & 97 & 3.5 & & 79.4 & \\
\hline \multicolumn{6}{|l|}{ Anorexia syndrome } \\
\hline No & 349 & 0.8 & $<0.0001^{\mathrm{a}}$ & 6.0 & $<0.0001^{\mathrm{a}, \mathrm{c}}$ \\
\hline Mild & 401 & 1.5 & & 22.0 & \\
\hline Moderate & 477 & 2.2 & & 41.5 & \\
\hline Severe & 224 & 3.0 & & 69.2 & \\
\hline \multicolumn{6}{|l|}{ Fatigue } \\
\hline No & 455 & 0.9 & $<0.0001^{\mathrm{b}}$ & 11.4 & $<0.0001^{\mathrm{a}}$ \\
\hline Mild & 536 & 1.7 & $<0.0001^{\mathrm{a}}$ & 23.5 & $<0.0001^{\mathrm{b}}$ \\
\hline Moderate & 359 & 2.6 & & 58.2 & \\
\hline Severe & 99 & 3.4 & & 75.8 & \\
\hline
\end{tabular}

${ }^{\text {a }} P$ value from the univariable analysis

${ }^{\mathrm{b}} P$ value from the multivariable analysis

${ }^{\mathrm{c}}$ Not included in the multivariable analysis
Recently, Odelli et al. [51] reported that when applying a periodic nutrition assessment of all oesophageal cancer patient metabolic investigations [49, 50] and in RCTs [46-48]. 
Table 3 Frequency of patients at nutritional risk (NRS score $\geq 3$ ), estimated by the multivariable logistic model

\begin{tabular}{lcccccc}
\hline \multirow{2}{*}{$\begin{array}{l}\text { Tumour } \\
\text { site }\end{array}$} & \multirow{2}{*}{ Anorexia } & Fatigue & \multicolumn{3}{l}{ ECOG performance status } \\
\cline { 3 - 7 } & & & $0(\%)$ & $1(\%)$ & $2(\%)$ & $3-4(\%)$ \\
\hline Lower GI & \multirow{2}{*}{ Absent } & Absent & 7.9 & 26.0 & 56.5 & 73.7 \\
& & Present & 15.2 & 42.2 & 73.0 & 85.4 \\
& \multirow{2}{*}{ Present } & Absent & 10.7 & 32.8 & 64.4 & 79.6 \\
& & Present & 37.0 & 70.5 & 89.9 & 95.0 \\
Upper GI & \multirow{2}{*}{ Absent } & Absent & 15.4 & 42.6 & 73.3 & 85.6 \\
& & Present & 27.5 & 60.7 & 85.1 & 92.5 \\
& \multirow{2}{*}{ Present } & Absent & 20.2 & 50.8 & 79.3 & 89.2 \\
& & Present & 55.4 & 83.5 & 94.9 & 97.6 \\
& \multirow{2}{*}{ Absent } & Absent & 9.6 & 30.0 & 61.4 & 77.4 \\
& & Present & 18.0 & 47.2 & 76.8 & 87.7 \\
& \multirow{2}{*}{ Present } & Absent & 12.8 & 37.4 & 68.9 & 82.7 \\
& & Present & 41.9 & 74.5 & 91.6 & 95.9 \\
Other & \multirow{2}{*}{ Absent } & Absent & 11.2 & 33.9 & 65.5 & 80.4 \\
& & Present & 20.8 & 51.6 & 79.8 & 89.5 \\
& \multirow{2}{*}{ Present } & Absent & 14.9 & 41.6 & 725 & 85.1 \\
& & Present & 46.2 & 77.7 & 92.8 & 96.5 \\
\hline & & & & & &
\end{tabular}

candidates to chemoradiation, they were able to identify patients at risk for malnutrition, to start early with nutritional support and to achieve a clinical benefit (less weight loss, greater radiotherapy completion, fewer and shorter unplanned hospital admission) as compared with a historical group of similar patients.

Furthermore Table 3 reports the probability for a patient to fall in a high NRS depending on the different combination of the site of primary tumour, presence or absence of some symptoms and values of the ECOG scale. It was not our intention to make a comparison with other screening methods, however it is worthy of note that these clinical variables together with some information on weight change, anorexia, performance status and gastrointestinal disturbances are commonly collected during the clinical oncologic examination and recorded in the chart. Moreover, body weight and height (and hence the BMI) are necessary to calculate the body area surface on which the doses of chemotherapeutics are calculated. Hence the presence of such variables can alert the clinician upon the potential onset of nutritionrelated problems. In such a way, the oncologist is able to suspect any condition of nutritional risk and consequently depending on the severity of the situation, can provide the patient with some simple preventative suggestions (i.e. anti-anorectic/anti-cachectic agents or nutritional supplementations) or to defer him/her to a specialised nutrition support team.
There are some points of weakness in the study. Despite the high number of patients, this study does not involve all types of tumour, and patients with urogenital, bone and soft tissue malignancies are underrepresented. Hence our results cannot be generalised to all cancer population. It is true, however, that the variables we identified as significant (namely deterioration of the performance status, anorexia, fatigue) are expression of the metabolic component and the severity of the disease rather than a marker of a specific tumour and have a prognostic relevance in a variety of tumours.

Furthermore, oncologic treatments were disparate as regards type, administration and time interval from examination/interview of the patients, and we cannot exclude that some particularly aggressive therapies may adversely affect the nutritional risk. In such cases, however, the oncologist is usually aware of the impact of the oncologic treatment on the nutritional status and hence more than a screening procedure, a strict active surveillance of the occurrence of the potential nutritional complications is required.

In conclusion, this study shows that a large population of cancer outpatients, about one third, presents a high nutritional risk. Even though oncologists may be unfamiliar with nutritional tools or nutritional risk scores, nevertheless, the determination of some simple factors as site of primary tumour, the performance status and the presence of some symptoms (anorexia and fatigue) may alert them about a condition of nutritional deterioration of their patients and the potential use of a nutritional support.

Acknowledgments The authors acknowledge Nestlé HealthCare for their help in the collection of data from the SCRINIO Centers. Participating centres and principal collaborators of the SCRINIO Working Group: Asti, Ospedale Card. Massaia: ML Amerio; Belo Horizonte (Brazil), University Hospital: I Correia; Candiolo, ASO MaurizianoPresidio IRCCS: L Rovera, R Bianco, P D'Elia; Cagliari, Ospedale Universitario: G Mantovani, E Massa, C Madeddu; Jeddah (Saudi Arabia), King Faisal Specialist Hospital and Research Center: A. Magzoub Hussein, S Eshki, K Bajunaid; Lucca, Presidio Ospedaliero: M Pellegrini, GR Barsanti, M Battistoni; Massa Carrara, ASL 1-Ospedale Civile: A Giannoni, L Sturlese, C Pennucci; Milano, Fondazione IRCCS Istituto Nazionale Tumori: C Gavazzi, C Arcovio, L Licitra; Milano, Istituto Europeo di Oncologia: R Biffi, D Papis, MG Zampino; Orbassano, AOU S. Luigi Gonzaga: P Avagnina, M Tinivella, C Fenoglio; Padova, Ospedale S. Antonio USSL 16: P Magnanini; Pavia, Fondazione IRCCS Policlinico San Matteo: R Caccialanza, B Cameletti, S Rocca; Pinerolo, ASL 10 - Ospedale Civile: V Sidoti, GM Rovera; Prato, Ospedale Misericordia e Dolce: F Bozzetti, A DiLeo; Roma, Ospedale San Pietro Fatebenefratelli: G Capuano, I Pavese, M Tosti; Roma, Ospedale S. Eugenio: G Sandri, P Pizzichino, GM Giorgetti; Rozzano, Istituto Clinico Humanitas: L Cozzaglio, L Despini; Siena, Az. Osp. Universitaria Senese "Le Scotte": L Di Cosmo; Tolmezzo, Ospedale S. Antonio Abate: E Vigevani; Torino, Ospedale S. Giovanni Battista: C Finocchiaro. 
Ethics approval All participating institutions got the approval of local ethics committee to study protocol and informed consent form.

Funding No funding supported this study.

Conflicts of interest The authors declare no potential conflicts that could inadvertently influence this work.
Data control statement The authors have full control of the primary data, and they agree to allow the journal to review their data if requested.

Open Access This article is distributed under the terms of the Creative Commons Attribution License which permits any use, distribution, and reproduction in any medium, provided the original author(s) and the source are credited.

\section{Appendix 1. Nutritional Risk Screening (NRS 2002)}

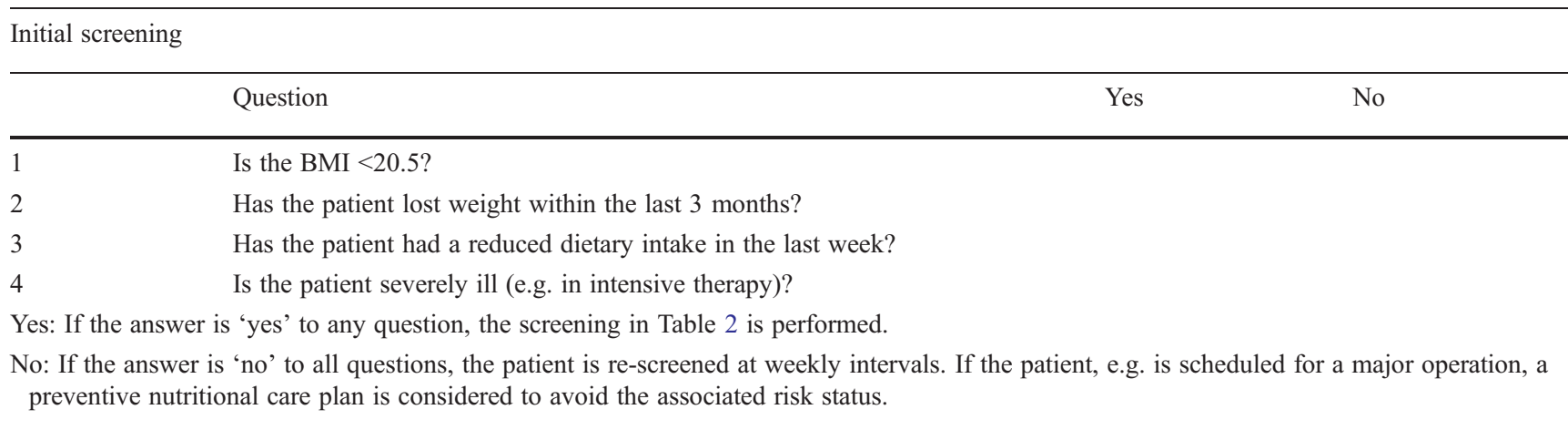

Final screening

Impaired nutritional status

Absent (score $=0)$
Mild (score $=1)$

Moderate $($ score $=2)$

Wt loss $45 \%$ in 2 months or BMI 18.5-20.5 + impaired general condition or food intake $25-60 \%$ of normal requirement in preceding week

Severe $($ score $=3)$ Wt loss $45 \%$ in 1 month ( $>15 \%$ in 3 months) or BMI $<18.5$ + impaired general condition or food intake $0-25 \%$ of normal requirement in preceding week

$\begin{array}{ll}\text { Score } & + \\ \text { Age } & \text { If } \geq 70 \text { years, add } 1 \text { to total score above }\end{array}$

Severity of disease ( $\approx$ increase in requirements)

\begin{tabular}{|c|c|}
\hline Absent $($ score $=0)$ & Normal nutritional requirements \\
\hline Mild $($ score $=1)$ & $\begin{array}{l}\text { Hip fracture, chronic patients, in particular } \\
\text { with acute complications: cirrhosis, } \\
\text { COPD, chronic hemodialysis, diabetes, } \\
\text { oncology }\end{array}$ \\
\hline Moderate $($ score $=2)$ & $\begin{array}{l}\text { Major abdominal surgery, stroke, severe } \\
\text { pneumonia, hematologic malignancy }\end{array}$ \\
\hline
\end{tabular}

Severe $($ score $=3)$

Head injury, bone marrow transplantation, intensive care patients (APACHE $>10$ )

Score $\quad=$ Total score

=Age-adjusted total score

\section{References}

1. Lochs H, Allison SP, Meier R et al (2006) Introductory to the ESPEN guidelines on enteral nutrition: terminology, definitions, and general topics. Clin Nutr 25:180-186

2. Kondrup J, Rasmussen HH, Hamberg O, Stanga Z, Ad Hoc ESPEN Working Group (2003) Nutritional risk screening (NRS 2002): a new method based on an analysis of controlled clinical trials. Clin Nutr 22:321-336
3. Elia M, Zellipour L, Stratton RJ (2005) To screen or not to screen for adult malnutrition? Clin Nutr 24:867-884

4. McWhirter JP, Pennington CR (1994) Incidence and recognition of malnutrition in 239 hospitals. BMJ 308:945-948

5. Orrevall Y, Tishelman C, Permert J, Cederholm T (2009) Nutritional support and risk status among cancer patients in palliative home care services. Support Care Cancer 17:153-161

6. Brown JK, Radke KJ (1998) Nutritional assessment, intervention, and evaluation of weight loss in patients with non-small cell lung cancer. Oncol Nurs Forum 25:547-553 
7. Huhmann MB, Cunningham RS (2005) The importance of the nutritional screening in the treatment of cancer-related weight loss. Lancet Oncol 6:334-343

8. Johansen N, Kondrup J, Plum LM et al (2004) Effect of nutritional support on clinical outcome in patients at nutritional risk. Clin Nutr 23:539-550

9. Bozzetti F, SCRINIO Working Group (2009) Screening the nutritional status in oncology: a preliminary report on 1,000 outpatients. Support Care Cancer 17:279-284

10. Mariani L, Lo Vullo S, Bozzetti F, On behalf of the SCRINIO Working Group (2012) Weight loss in cancer patients: a plea for a better awareness of the issue. Support Care Cancer 20(2):301-309

11. Bozzetti F, Mariani L (2009) Defining and classifying cancer cachexia: a proposal by the SCRINIO Working Group. JPEN J Parenter Enteral Nutr 33:361-367

12. Stewart GD, Skipworth RJ, Fearon KC (2009) The anorexia-cachexia syndrome. In: Walsh D (ed) Palliative medicine. Saunders Elsevier, Philadelphia, pp 587-595

13. American Society for Parenteral and Enteral Nutrition Board of Directors (2002) Guidelines for the use of parenteral and enteral nutrition in adult and pediatric patients. JPEN J Parenter Enteral Nutr 26(1 Suppl):1SA-138SA

14. Mueller C, Compher C, Ellen DM, The American Society for Parenteral and Enteral Nutrition (ASPEN) Board of Directors (2011) ASPEN clinical guidelines: nutrition screening, assessment, and intervention in adults. JPEN J Parenter Enteral Nutr 35:16-24

15. National Cancer Institute (2008) Nutrition implications of cancer therapies. http://www.cancer.gov/cancertopics/pdq/supportivecare/ nutrition/HealthProfessional/page3. Accessed $22 \mathrm{Feb} 2011$

16. Spiro A, Baldwin C, Patterson A, Thomas J et al (2006) The views and practice of oncologists towards nutritional support in patients receiving chemotherapy. Br J Cancer 95:431-434

17. DeCicco PV, Wunderlich SM, Emmolo JS (2010) Determination of malnourishment in the head and neck cancer patient: assessment tools and nutrition education of radiation oncologists. Support Care Cancer 19:123-130

18. Ferguson M, Capra S, Bauer J, Banks M (1999) Development of a valid and reliable malnutrition screening tool for adult acute hospital patients. Nutrition 15:458-464

19. Ferguson ML, Bauer J, Gallagher B et al (1999) Validation of a malnutrition screening tool for patients receiving radiotherapy. Australas Radiol 43:325-327

20. Amaral TF, Antunes A, Cabral S et al (2008) An evaluation of three nutritional screening tools in a Portuguese oncology centre. J Hum Nutr Diet 21:575-583

21. Bauer J, Capra S (2003) Comparison of a malnutrition screening tool with subjective global assessment in hospitalised patients with cancer - sensitivity and specificity. Asia Pac J Clin Nutr 12:257-260

22. Ottery FD (1996) Definition of standardized nutritional assessment and interventional pathways in oncology. Nutrition 12(Suppl 1): S15-S19

23. Read JA, Crockett N, Volker DH et al (2005) Nutritional assessment in cancer: comparing the Mini-Nutritional Assessment (MNA) with the scored Patient-Generated Subjective Global Assessment (PGSGA). Nutr Cancer 53:51-56

24. Bauer J, Capra S, Ferguson M (2002) Use of the scored Patient-Generated Subjective Global Assessment (PG-SGA) as a nutrition assessment tool in patients with cancer. Eur J Clin Nutr 56:779-785

25. Segura A, Pardo J, Jara C et al (2005) An epidemiological evaluation of the prevalence of malnutrition in Spanish patients with locally advanced or metastatic cancer. Clin Nutr 24:801-814

26. Unsal D, Mentes B, Akmansu M et al (2006) Evaluation of nutritional status in cancer patients receiving radiotherapy: a prospective study. Am J Clin Oncol 29:183-188
27. Sungurtekin H, Sungurtekin U, Balci C et al (2004) The influence of nutritional status on complications after major intraabdominal surgery. J Am Coll Nutr 23:227-232

28. NCD Association (2004) Skill-building success! The Link, The North Carolina Dietetic Association Newsletter. 3:5

29. Kyle UG, Kossovsky MP, Karsegard VL, Pichard C (2006) Comparison of tools for nutritional assessment and screening at hospital admission: a population study. Clin Nutr 25:409-417

30. Roulston F, McDermott R (2008) Comparison of three validated nutritional screening tools in the oncology setting. Proc Soc Nutr 67(OCE7):E260

31. Sorensen J, Kondrup J, Prokopowicz J, EuroOOPS study group (2008) EuroOOPS: an international, multicentre study to implement nutritional risk screening and evaluate clinical outcome. Clin Nutr 27:340-349

32. Isenring E, Cross G, Kellett E, Koczwara B, Daniels L (2010) Nutritional status and information needs of medical oncology patients receiving treatment at an Australian public hospital. Nutr Cancer 62:220-228

33. Gur AS, Atahan K, Aladag I et al (2009) The efficacy of Nutrition Risk Screening-2002 (NRS-2002) to decide on the nutritional support in general surgery patients. Bratisl Lek Listy 110:290-292

34. Schiesser M, Müller S, Kirchhoff P et al (2008) Assessment of a novel screening score for nutritional risk in predicting complications in gastro-intestinal surgery. Clin Nutr 27:565-570

35. Korfali G, Gündoğdu H, Aydintuğ S et al (2009) Nutritional risk of hospitalized patients in Turkey. Clin Nutr 28:533-537

36. Orreval Y, Tishelman C, Cederholm T (2009) Nutritional support and risk status among cancer patients in palliative home care service. Support Care Cancer 17:153-161

37. Arrieta O, Michel Ortega RM, Villanueva-Rodríguez G et al (2010) Association of nutritional status and serum albumin levels with development of toxicity in patients with advanced non-small cell lung cancer treated with paclitaxel-cisplatin chemotherapy: a prospective study. BMC Cancer 10:50

38. Aslani A, Smith RC, Allen BJ et al (2000) The predictive value of body protein for chemotherapy-induced toxicity. Cancer 88:796-803

39. Tubiana M, Attié E, Flamant R et al (1971) Prognostic factors in 454 cases of Hodgkin's disease. Cancer Res 31:1801-1810

40. Ovesen L, Allingstrup L, Hannibal J et al (1993) Effect of dietary counseling on food intake, body weight, response rate, survival, and quality of life in cancer patients undergoing chemotherapy: a prospective, randomized study. J Clin Oncol 11:2043-2049

41. Aviles A, Yañez J, López T et al (1995) Malnutrition as an adverse prognostic factor in patients with diffuse large cell lymphoma. Arch Med Res 26:31-34

42. Andreyev HJ, Norman AR, Oates J, Cunningham D (1998) Why do patients with weight loss have a worse outcome when undergoing chemotherapy for gastrointestinal malignancies? Eur J Cancer 34:503-509

43. Mitry E, Douillard JY, Van Cutsem E et al (2004) Predictive factors of survival in patients with advanced colorectal cancer: an individual data analysis of 602 patients included in irinotecan phase III trials. Ann Oncol 15:1013-1017

44. Ross PJ, Ashley S, Norton A et al (2004) Do patients with weight loss have a worse outcome when undergoing chemotherapy for lung cancers? Br J Cancer 90:1905-1911

45. Van Eys J (1982) Effect of nutritional status on response to therapy. Cancer Res $42(2$ suppl): $747 \mathrm{~s}-753 \mathrm{~s}$

46. Isenring EA, Capra S, Bauer JD (2004) Nutrition intervention is beneficial in oncology outpatients receiving radiotherapy to the gastrointestinal or head and neck area. Br J Cancer 91:447-452

47. Ravasco P, Monteiro-Grillo I, Marques Vidal P, Camilo ME (2005) Impact of nutrition on outcome: a prospective randomized controlled 
trial in patients with head and neck cancer undergoing radiotherapy. Head Neck 27:659-668

48. Ravasco P, Monteiro-Grillo I, Vidal PM, Camilo ME (2005) Dietary counseling improves patient outcomes: a prospective, randomized, controlled trial in colorectal cancer patients undergoing radiotherapy. J Clin Oncol 23:1431-1438

49. Shaw JH, Wolfe RR (1988) Whole-body protein kinetics in patients with early and advanced gastrointestinal cancer: the response to glucose infusion and total parenteral nutrition. Surgery 103:148-155

50. Dillon EL, Volpi E, Wolfe RR et al (2007) Amino acid metabolism and inflammatory burden in ovarian cancer patients undergoing intense oncological therapy. Clin Nutr 26:736-743

51. Odelli C, Burgess D, Bateman L et al (2005) Nutrition support improves patient outcomes, treatment tolerance and admission characteristics in oesophageal cancer. Clin Oncol (R Coll Radiol) 17:639-645 